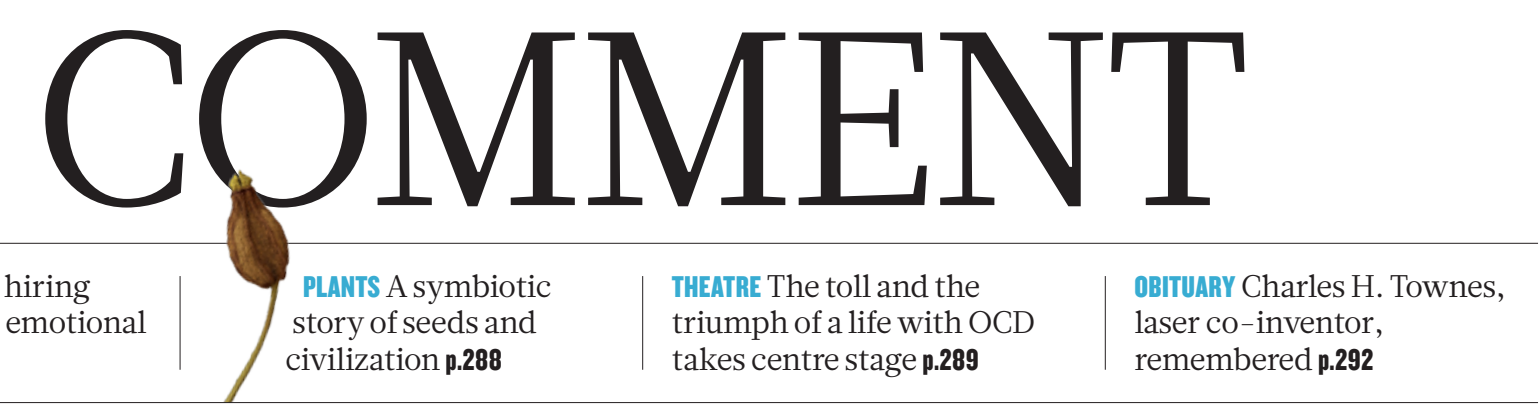

RECRUITMENT Tips for hiring leaders emphasize emotional intelligence $\mathbf{p . 2 8 6}$ story of seeds and civilization $\mathbf{p . 2 8 8}$
The toll and the

laser co-inventor, remembered $\mathbf{p . 2 9 2}$

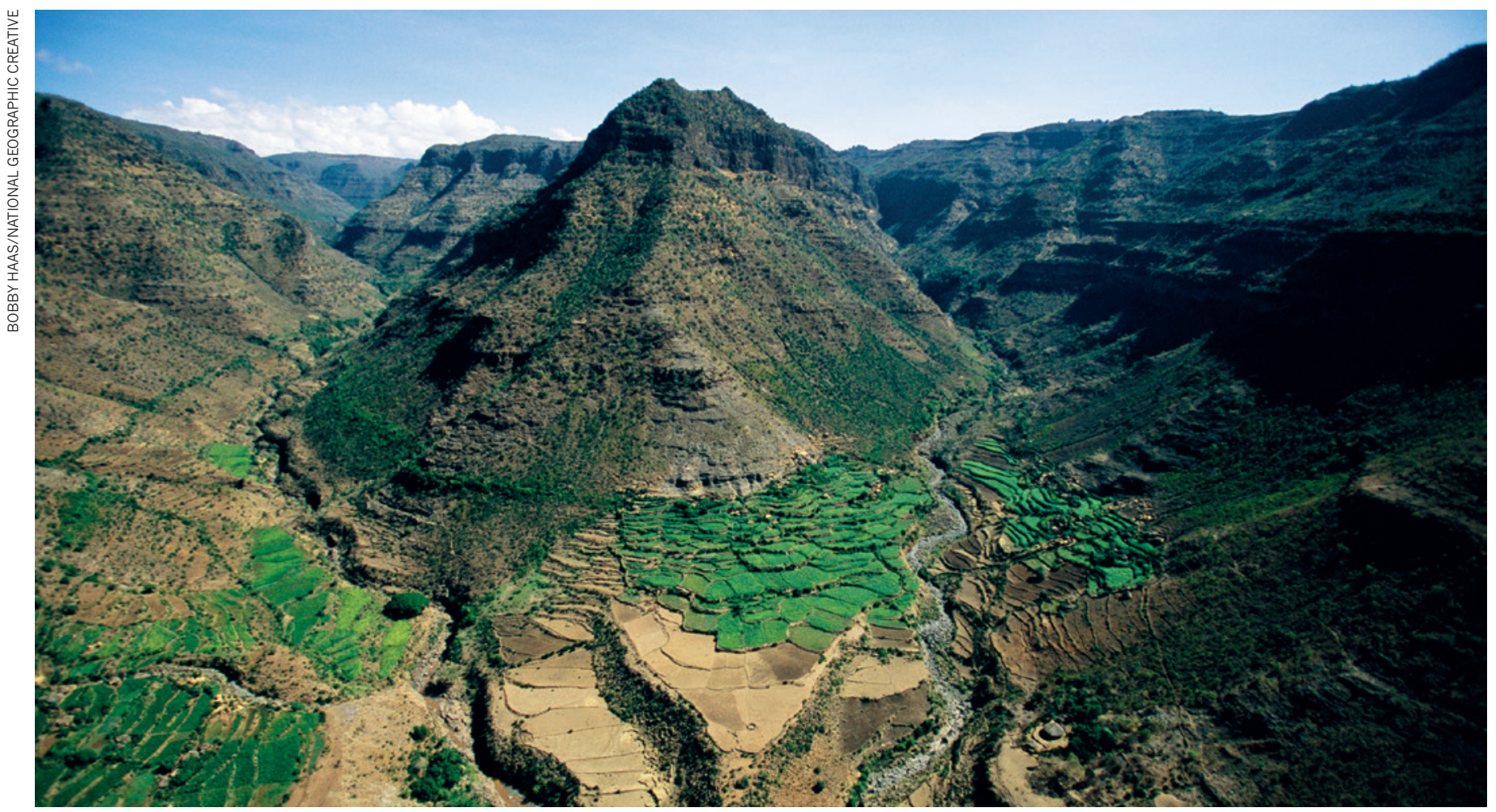

Terraced fields in the Simien Mountains, Ethiopia, help to conserve soil moisture.

\title{
Increase water harvesting in Africa
}

\section{Meeting global food needs requires strategies for storing rainwater and retaining} soil moisture to bridge dry spells, urge Johan Rockström and Malin Falkenmark.

$\mathrm{E}$ nsuring that the world's food needs are met by 2050 will take a doubling of global food production ${ }^{1}$. To improve agricultural yields on that scale will require a radical rethink of global water-management strategies and policies.

Sub-Saharan Africa is the epicentre of this challenge. The region's population is set to more than double by 2050 to almost 2.5 billion, or $25 \%$ of the world's projected population ${ }^{2}$. Half of its current one billion inhabitants lives in extreme poverty, one-quarter is undernourished, and onefifth faces serious water shortages. Although almost two-thirds of the population are rural, agriculture on much of the land is limited by scarce, variable and unpredictable water resources ${ }^{3}$.

Ninety-five per cent of sub-Saharan agriculture depends on 'green water': moisture from rain held in the soil. In large parts of the continent, most rain evaporates before it generates 'blue water', or run-off, so little of it recharges rivers, lakes and groundwater.
Most farming communities are a long way from rivers ${ }^{4}$ and cannot use irrigation. Arid deserts and semi-arid savannahs comprise $40 \%$ of the region's land area. These receive too little surface run-off (less than 100 millimetres a year) to grow maize (corn), rice, millet and sorghum (which requires at least $400 \mathrm{~mm}$ per year) using irrigation alone. Future rainfall will be more variable and could be $25 \%$ lower in many semi-arid regions if average global temperatures warm by $2{ }^{\circ} \mathrm{C}$ above pre-industrial levels 5 . 
AFRICAN DRYLANDS Rainfall and run-off across drylands in sub-Saharan Africa is too low and variable to use irrigation to grow staple food crops such as maize (corn), millet and sorghum.
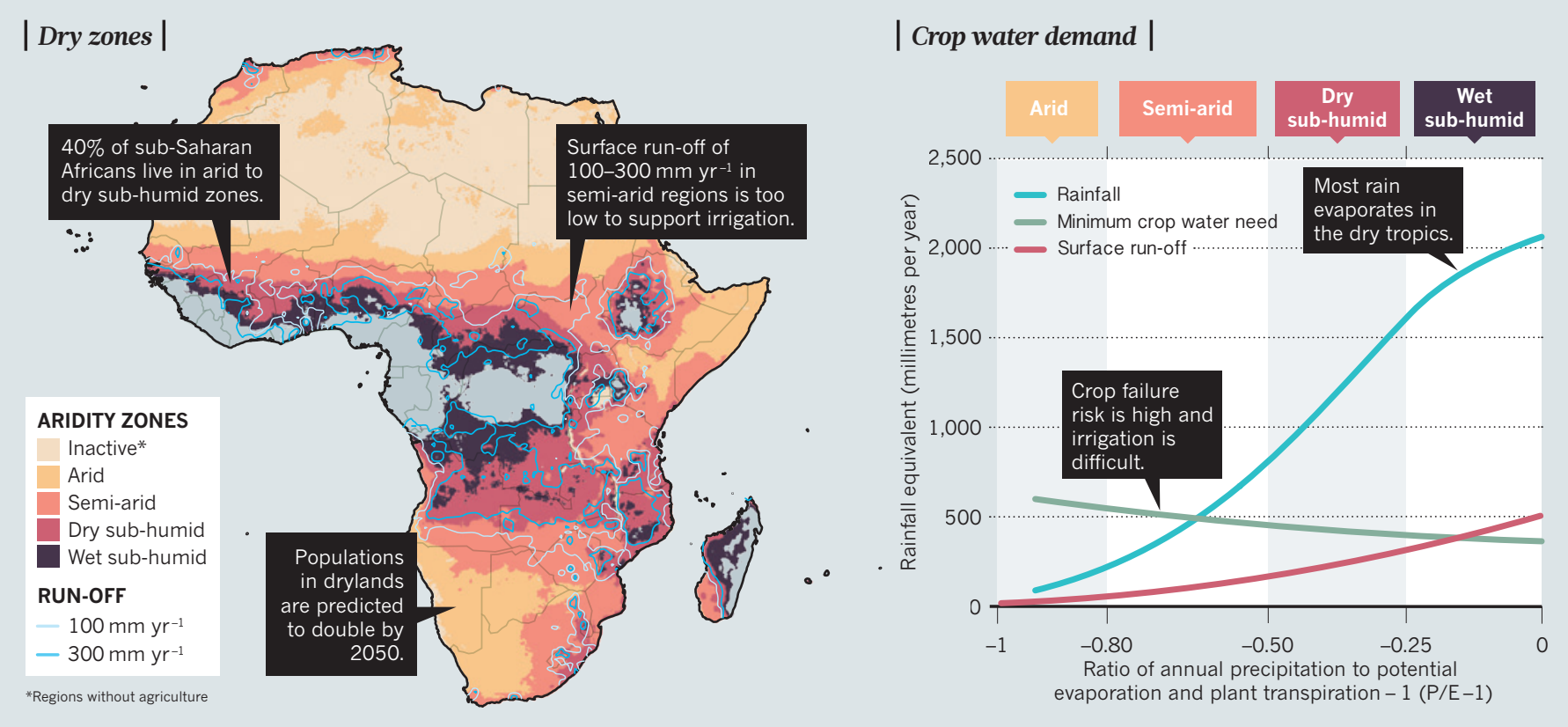

> Management of green water for rain-fed, small-scale farming is integral to eradicating hunger. But it is missing from the draft United Nations Sustainable Development Goals (SDGs), which will be agreed in September. A dedicated water goal that includes science-based targets and indicators is essential and must receive attention during the SDG negotiations in New York next week, in the wake of the World Water Day on 22 March.

We propose an approach for the SDG goal that will improve water security, address hunger and poverty and enhance carbon storage. Retaining more rainwater in soils and storing run-off would bridge dry spells that last weeks, the major challenge to rainfed food production. For longer droughts, social and economic strategies are needed to assure food security.

\section{UNTAPPED POTENTIAL}

Water flows across the SDGs - from improving water, sanitation and health to ending hunger and poverty. But there has been no discussion so far about how water resources should be managed to meet the aims. The goals are vague and assume - as have global water policies for decades - that water for all needs can be drawn from rivers, lakes and groundwater.

This blue-water bias stems from the modernization of water infrastructure starting in the 1950s, when most dams and pumping stations were built. Since then, water management has been viewed mainly as an engineering challenge. Conventional green-water practices, such as soil and water conservation and water harvesting, are seeing a resurgence worldwide in areas where irrigation is impractical. But the importance of supporting rain-fed agriculture has not yet been translated into investment strategies and policies for development.

Regions in which irrigation is not viable include highly populated places such as Africa's Sahel region, northern China and central India. In sub-Saharan Africa, almost 500 million people live in dry zones deserts, grasslands and bush savannahs - in countries such as Mali, Niger and Zimbabwe. Another 245 million live in slightly wetter zones with forest savannahs, for example in large parts of Tanzania and Zambia, where run-off is still too low to irrigate fields (see 'African drylands'). In any case, river water is needed mainly for urban, industrial and energy needs.

When crops fail, the reason is usually an extended dry spell, or one at a crucial point in the growing season, such as the flowering period, rather than low rainfall. Several weeks without rain are common and may occur each season, sometimes with a devastating effect. In 2000, when an early onset of the rainy season followed by 6-9 weeks without rain prevented staple crops such as maize from growing in Kenya, 4 million people across the country faced severe food shortages.

Rainfall is becoming more erratic. Zambia, Malawi and Zimbabwe have experienced later rainy seasons, longer dry spells and fewer rainy days over the past 50 years than before ${ }^{6}$. The cause is uncertain but may be linked to anthropogenic climate change.

Water losses compound the difficulties of farming in dry tropical regions. Field research shows that $50-70 \%$ of rainfall does not reach crops but evaporates or becomes surface runoff (causing soil erosion), recharging water tables (see 'Sub-Saharan water balance'). Guiding more water to the root zone would dramatically improve food production ${ }^{7}$.

\section{WATER HARVESTING}

Green water can be retained in three ways: collecting run-off; improving the infiltration of rain in soils; and managing land, water and crops across watersheds to increase water storage in soils, wetlands and the water table ${ }^{7}$.

Small-scale water harvesting methods include terracing to conserve soil moisture, as in the famous Fanya-juu terraces of Machakos, Kenya; or using dams and ditches to channel run-off into fields, as widely used in Eritrea and Israel. Storage systems such as ponds, tanks and sub-surface storage in sand and soil, used in places such as northern Mexico, Ethiopia, Sudan and India, offer another approach. Together these systems can hold the equivalent of a few rainy-season deluges, enough to bridge month-long dry spells.

Water harvesting has been introduced to several parts of Africa, including Kenya and Tanzania, since the 1980 s by nongovernmental and development organizations including the UN. It has improved the stability of crop yields and can raise productivity from 1 tonne per hectare to 3-4 tonnes ${ }^{8}$.

The technique is also proven elsewhere. In India, some state governments and community organizations have revived water-harvesting methods. The state of Karnataka has in all its 30 districts piloted integrated land and water management - including water 
harvesting - raising crop productivity. Dams, gullies and ponds combined with improved water, nutrient and crop management have increased Indian crop yields from around 1 tonne per hectare to 5 tonnes $^{7}$. China's arid Gansu province supplies water to the homes of 2 million people using small, spherical sub-surface tanks to collect rainwater, and is increasingly using water harvesting in agriculture ${ }^{9}$.

Soil, nutrient and crop-management strategies are also needed to boost yields. One of the most promising practices is abandoning the plough, which has proven to be an effective way of burning soil carbon - by exposing it to sun and oxygen - causing emissions of carbon dioxide. Ploughing compacts and encrusts the soil, preventing rain from infiltrating and increasing run-off. Conservation tillage instead avoids turning the soil to allow its structure and microorganisms to build up.

Applied to the world's croplands, conservation tillage could increase carbon uptake by up to 1 gigatonne of carbon per year, or one-ninth of current global emissions ${ }^{10}$. It would have three benefits: mitigating climate change; increasing crop yields by adding green water; and reducing soil degradation through lower surface run-off. Used on more than one-third of US farmland, such methods are increasingly being adopted in Africa, for example in Ethiopia, Zambia and Zimbabwe.

Mulches and canopy cover cut evaporation. The limiting factor is the extremely nutrientpoor soils across savannah farming systems, particularly in Africa. Nutrients can be added through fertilizers, manure and composts. Raising nutrient applications from the current African average of less than 10 kilograms of nitrogen and phosphorus per hectare per year

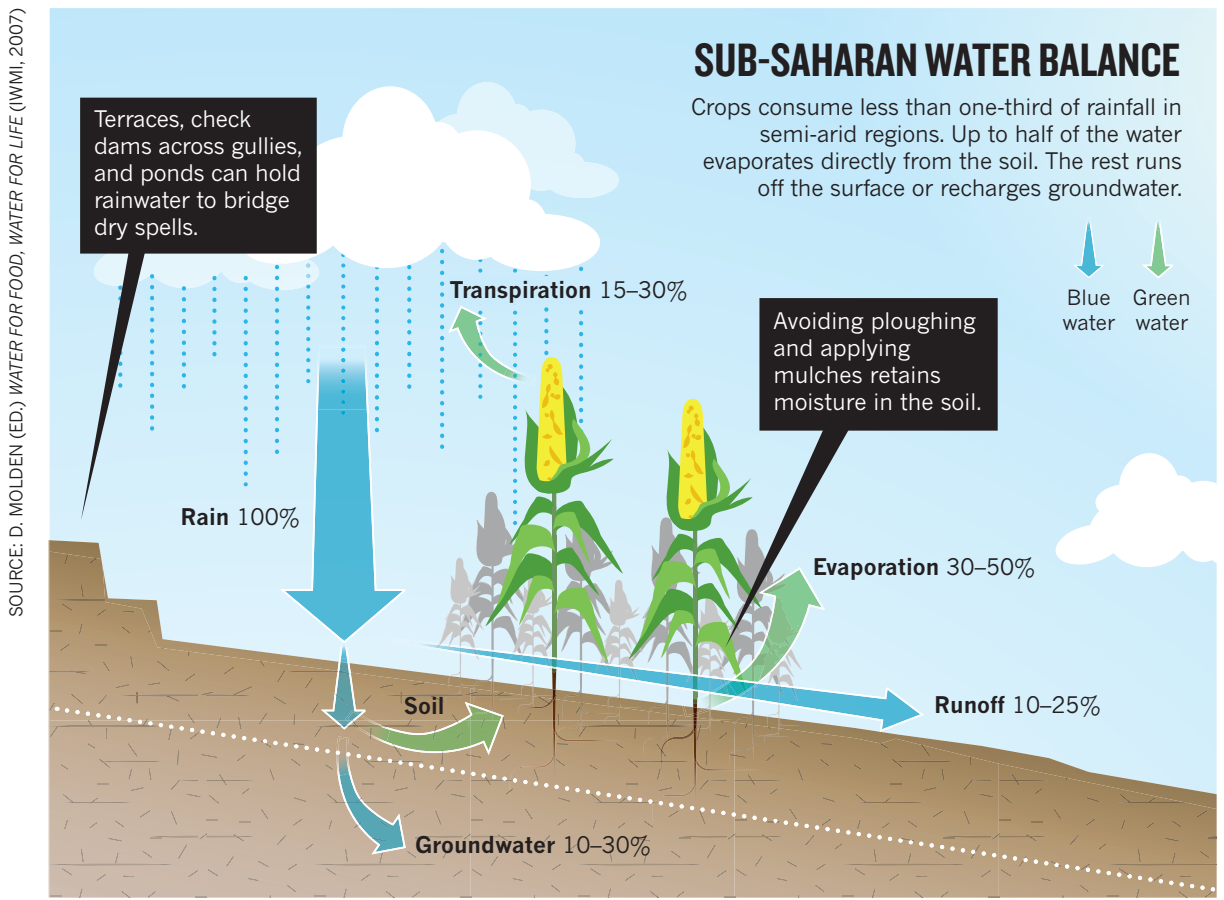

to $50-100 \mathrm{~kg}$ (still less than the global average) could boost productivity many times over.

Green-water-management strategies need to span scales - from fields to watersheds and river basins. Diverse sets of ecosystems should be protected to dampen the effects of flash floods and encourage underground flows to avoid erosion from run-off. Wetlands, meandering rivers, forests and patchy landscapes are natural capital assets that build resilience.

Watershed and river-basin management also protect local rainfall. Much tropical rain is convective - clouds produced from rising vapour over forests generate rain downwind. For instance, moisture from the West African rainforests in the south causes rain to fall on

\section{FOOD SECURITY}

Rapid population growth ${ }^{2}$ however means that even with the most optimistic yield improvements it is unlikely that Africa will be self-sufficient in food by 2050. Particularly at risk are countries in the Sahel region, northern Africa and the Horn of Africa.

Food trade will be necessary to supplement crop growth for at least 30 African nations ${ }^{3}$. This calls for economic development industries supported by blue water - to generate purchasing power. Regional economic policies that protect national food production while facilitating food trade will be needed. Emergency responses will also be required to cope with inevitable crop failure. These could include resilience strategies such as socialsecurity systems, cereal banks and insurance to compensate farmers for crop failure.

Sustainable development of sub-Saharan Africa needs to be based on a fine balance of

\section{SUB-SAHARAN WATER BALANCE}

ps consume less than one-third of rainfall in semi-arid regions. Up to half of the water and ponds can hold rainwater to bridge Transpiration $15-30 \%$ and applying mulches retains moisture in the soil. the semi-arid savannah in the north.

\section{(n)}

colnuENT i-

blue and green water: blue water for urbanization, industrialization and energy development, and green water for food and biomass production.

The SDG framework should reflect this integrated water agenda. A specific target on sustainable management of rainfall for ecosystems and food production in water-scarce regions of the world is necessary to fulfil the goals on eradicating hunger and poverty and enabling long-term economic development.

Large institutions and foundations that invest in African development, such as the African Development Bank, the World Bank and the Alliance for a Green Revolution in Africa initiative, should invest in capacity development, planning and infrastructure development for small-scale water harvesting systems. The costs are large: investments of around US $\$ 10$ billion to $\$ 20$ billion per year for 10-15 years would be needed, comparable with those for basic sanitation, infrastructure and water supply. But they offer returns in terms of development and resilience.

National governments need policy shifts. Water and agriculture are typically handled by separate ministries. Water and food need to be integrated and managed in the same political sphere, preferably together with the environment, to enable sustainable and efficient blue- and green-water management in agricultural ecosystems and landscapes.

Hiding the African Achilles' heel of water scarcity behind unclear wording in the SDGs is a grave mistake. Without connecting water, food, growth and poverty, the sustainable development framework will not deliver on its promise to Africa.

Johan Rockström is professor of water systems and global sustainability, and director of the Stockholm Resilience Centre, Stockholm University, Sweden; and chair of the CGIAR Research Program on Water, Land and Ecosystems. Malin Falkenmark is professor of applied international hydrology at the Stockholm Resilience Centre, Stockholm University, Sweden, and senior scientific adviser to the Stockholm International Water Institute, Stockholm University, Sweden. e-mail:johan.rockstrom@su.se

1. IAASTD. Agriculture at a Crossroads: Global Report (eds Mclntyre, B. D., Herren, H. R., Wakhungu, J. \& Watson, R. T.) (Island Press, 2009).

2. Gerland, P. et al. Science 346, 234-237 (2014)

3. Rockström, J. et al. Water Resilience for Human Prosperity (Cambridge Univ. Press, 2014).

4. Vörösmarty, C. J., Douglas, E. M., Green, P. A., \& Revenga, C. AMBIO 34, 230-236 (2005).

5. Schewe, J. et al. Proc. Natl. Acad. Sci. USA 111, 3245-3250 (2013).

6. Tadross, M. et al. Climate Res. 40, 147-161 (2009).

7. Wani, S. P., Rockström, J. \& Oweis, T. (eds) Rainfed Agriculture: Unlocking the Potential (CABI, 2009).

8. Rockström, J. \& Falkenmark, M. Crit. Rev. Plant Sci. 19, 319-346 (2000).

9. Zhu, Q. \& Yanhong, L. Waterlines 24, 4-7 (2006).

10.Lal, R. Science 304, 1623-1627 (2004). 